\title{
FINITE ELEMENT MODELING OF REINFORCED CONCRETE STRUCTURAL WALLS FOR PERFORMANCE-BASED SEISMIC DESIGN
}

\author{
KRISTIJAN KOLOZVARI ${ }^{1}$, ROSS MILLER ${ }^{1} \&$ KUTAY ORAKCAL $^{2}$ \\ ${ }^{1}$ Department of Civil and Environmental Engineering, California State University, USA \\ ${ }^{2}$ Department of Civil Engineering, Bogazici University, Turkey
}

\begin{abstract}
A novel finite element modeling approach for nonlinear analysis of reinforced concrete (RC) structural walls is developed and implemented in OpenSees, which is an open-source computational platform widely used in earthquake engineering. The proposed analytical model incorporates a twodimensional RC constitutive panel behavior described with the fixed-strut angle model into a fournode isoparametric quadrilateral finite element model formulation. The modeling approach is used to simulate the responses of two medium-rise RC wall specimens (aspect ratios of 1.5 and 2.0) with predominant shear-flexure interaction responses. Based on detailed comparison of experimental and analytical wall responses, the model is found to be capable of predicting accurately the experimentally-measured response attributes of the cyclic nonlinear wall behavior including lateral strength, stiffness, stiffness degradation, as well as their hysteretic response characteristics. The model also captures interaction between flexural and shear behavior, and provides accurate estimates of the relative contribution of nonlinear flexural and shear deformations to wall lateral displacements and their distributions over the wall height. Finally, the proposed modeling approach describes reasonably well local response characteristics including magnitudes and distributions of strain and stress fields, as well as cracking patterns. Based on the response comparisons presented, model capabilities are assessed and possible model improvements are identified.

Keywords: reinforced concrete, structural walls, finite element modeling, performance-based design.
\end{abstract}

\section{INTRODUCTION}

Reinforced concrete (RC) structural walls are the most commonly used structural elements in buildings to resist lateral loads imposed by earthquakes. They are designed and detailed to provide adequate stiffness, strength and deformation capacity to achieve favorable structural performance under moderate and severe seismic demands. Use of nonlinear building models subjected to ground acceleration time-histories generally allows for a more reliable assessment of system and element demands (e.g., lateral story drift, wall shear demand, local strains or rotations), which are then compared with limits to judge if acceptable performance is expected. This design methodology, called Performance-Based Seismic Design (PBSD), has become very common in regions where moderate-to-strong earthquake shaking is anticipated, and it greatly relies on accuracy of nonlinear analysis approaches used to assess the expected performance of existing buildings (e.g., using ASCE 41-13 [1]) or to design new buildings (e.g., using Los Angeles Tall Buildings [2]). Because RC walls are the primary, and often the only lateral load resisting structural elements in building structures, the availability of analytical models that are capable of predicting important behavioral characteristics of their nonlinear seismic behavior is essential for reliable implementation of PBSD.

Over the past decade, a great number of numerical approaches with various levels of sophistication were introduced to simulate the nonlinear behavior of $\mathrm{RC}$ walls. The majority of proposed models that are widely used in engineering practice are macroscopic, based on a beam-column element formulation, where wall cross-section is discretized using 
a number of concrete and steel longitudinal fibers. These so-called fiber models have shown to be capable of predicting the nonlinear behavior of slender (flexure-controlled) RC walls reasonably well in terms of global wall responses (i.e., load-deformation behavior), whereas local responses (e.g., strains, rotations) are generally not predicted accurately due to simplifying assumptions used in model development, such as commonly used plane sections remain plane assumption. Furthermore, most of the models used in practice are not capable capturing the experimentally observed interaction between flexural and shear responses typically pronounced for structural walls with moderate aspect ratios (between 1.0 and 3.0). Experimental studies revealed that for such walls both flexural yielding and nonlinear shear deformations occur simultaneously, where shear deformations can constitute up to $30 \%$ to $50 \%$ of lateral wall displacements (e.g., Tran and Wallace [3]), and could lead to reduced wall strength, stiffness and deformation capacity. Fiber-based modeling methodologies commonly used in practice for PBSD of buildings typically consider uncoupled shear and flexural response components, where shear strength and stiffness are calculated according to code provisions and entered as an ad-hoc input parameter in the model. This relatively crude approximation of shear behavior does not capture accurately the mechanics of wall behavior under lateral loading (e.g., effect of axial load to shear strength and stiffness is not considered), which leads to underestimation of compressive strains even in relatively slender RC walls controlled by flexure (Orakcal and Wallace [4]), and overestimation of the lateral load capacity of RC walls with moderate aspect ratios (Kolozvari [5]) and low aspect ratios (Massone et al. [6]). Given mentioned shortcomings of analytical approaches currently used in engineering practice for implementation PBSD, there is a need for relatively simple modeling approaches for RC walls that consider interaction (coupling) between axial, flexural, and shear responses, and capture important global and local hysteretic response features for a wide range of wall geometries and reinforcing details.

A relatively simple yet accurate finite element modeling methodology based on a fixedcrack angle constitutive panel behavior was recently developed and implemented in OpenSees (McKenna et al. [7]), which is an open-source computational platform widelyused in earthquake engineering worldwide, for improved predictions of hysteretic nonlinear behavior of RC walls. This paper presents the results of validation studies of the proposed model formulation against experimental results obtained for two RC wall specimens (Tran and Wallace [3]) that experienced significant flexural yielding and nonlinear shear deformations. Model predictions were compared with the experimentally-measured wall responses at various response levels and location to provide comprehensive assessment of model capabilities and propose future model improvements.

\section{ANALYTICAL MODEL DESCRIPTION}

\subsection{Finite element model formulation}

The finite element model formulation presented in this study is an extension of the modeling approach adopted by Gullu and Orakcal [8]. A four-node bilinear iso-parametric quadrilateral element formulation (Cook et al. [9]) is used herein, for simulating the behavior of RC structural wall model elements. The model element formulation is characterized with two degrees of freedom (DOFs) per node (displacements in horizontal and vertical directions) and four Gauss integration points (Fig. 1). A two-dimensional strain field corresponding to plane-stress condition is obtained at each integration points based on displacements at element DOFs using bilinear interpolation functions. Material constitutive 
models that represent the behavior of concrete and reinforcing steel (described in the following section) are used at each integration point to obtain corresponding stress and stiffness properties. These quantities are then integrated over the element to obtain element nodal forces and stiffness values.

\subsection{Reinforced concrete panel behavior}

A plane-stress constitutive model called the Fixed Strut Angle Model (FSAM, Fig. 2; Orakcal et al. [10]) is used to define strain-stress behavior at each integration point within the implemented finite element formulation.

FSAM is an in-plane, reversed-cyclic constitutive model based on the fixed-crack angle modeling approach and assumption of perfect bond between concrete and reinforcing steel bars, i.e., no slip between concrete and steel reinforcement. The reinforcing bars develop uniaxial stresses under uniaxial strains in their longitudinal directions (Fig. 2(d)), whereas concrete behavior is based on uniaxial stress-strain relationships applied in biaxial directions, with orientations determined by the state of concrete cracking (Fig. 2(b)).
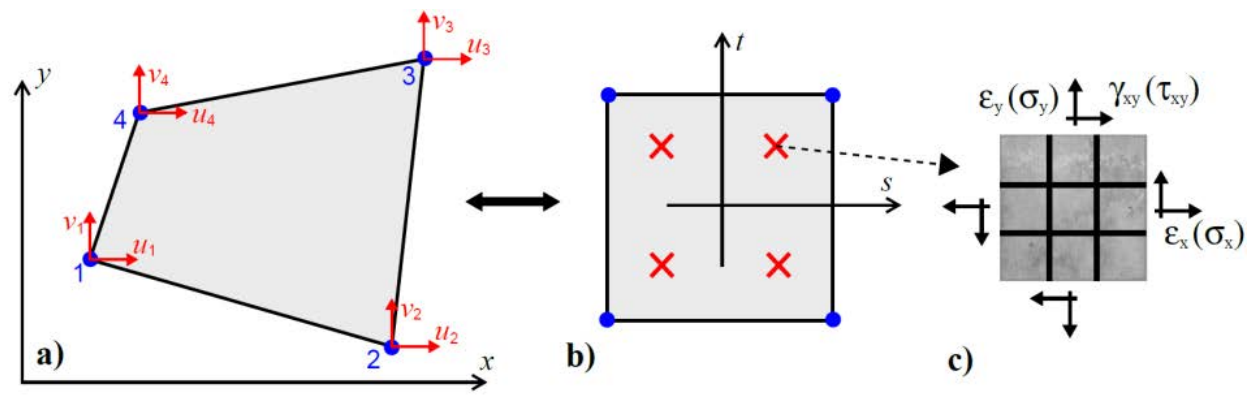

Figure 1: Four-node iso-parametric quadrilateral element. (a) Actual element; (b) Parent element; and (c) 2-D constitutive material model FSAM.

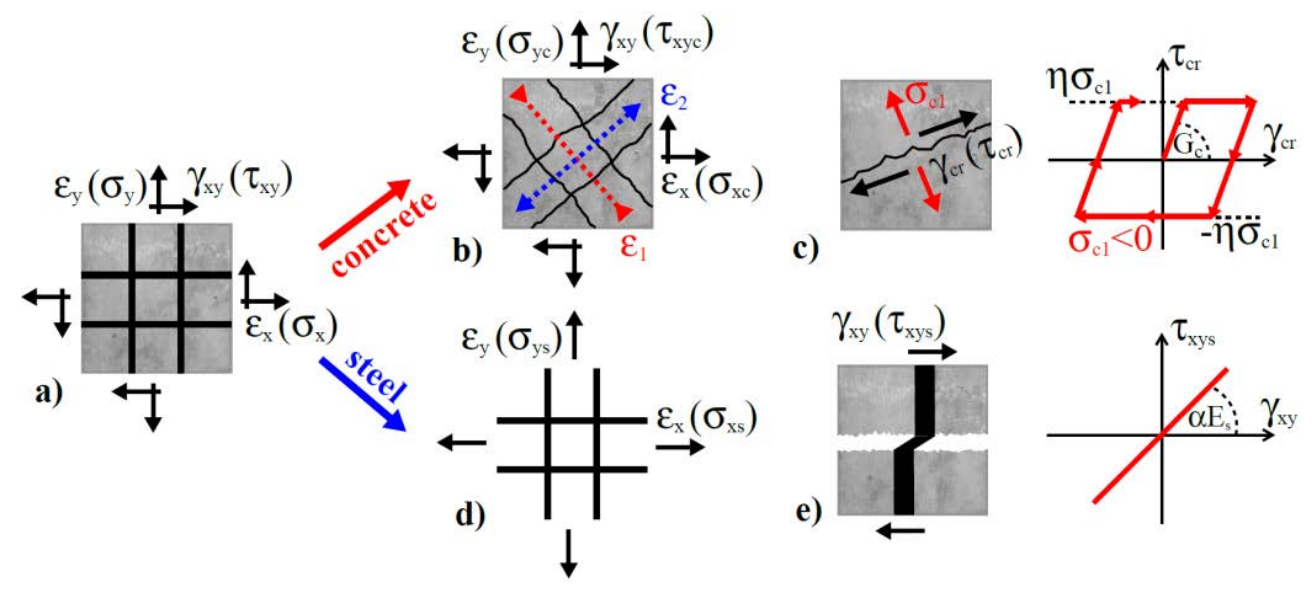

Figure 2: Behavior and modeling parameters of the constitutive RC panel model FSAM. (a) Strain-stress field; (b) Concrete biaxial behavior; (c) Concrete shear aggregate interlock; (d) Steel behavior; and (e) Dowel action on reinforcement. 
Concrete behavior is characterized by three consecutive stages: (a) uncracked concrete, (b) after formation of the first crack, and (c) after formation of the second crack, as described by Orakcal et al. [10]. Although the concrete stress-strain relationship is fundamentally uniaxial in nature, it also incorporates biaxial softening effects including compression softening (Vecchio and Collins [11]) and hysteretic biaxial damage (Mansour et al. [12]). In this study, the uniaxial constitutive model for concrete by Yassin [13] and the stressstrain relationship for steel proposed by Menegotto and Pinto [14] are used in the FSAM formulation. In addition, the shear resisting mechanisms along crack surfaces in the FSAM are described using a friction-based shear aggregate interlock model (Orakcal et al [ 10 ], Fig. 2(c)) and a linear-elastic model (Kolozvari et al. [15]) to account for dowel action on reinforcing steel bars (Fig. 2(e)).

\section{EXPERIMENTAL PROGRAM}

Experimental data obtained from two well-instrumented RC wall specimens tested by Tran and Wallace [3] were used to validate the proposed analytical model. Specimens were tested to failure under constant axial load and a reversed-cyclic displacement history applied at the wall top. Wall specimens considered in this study were characterized with aspect ratios of 1.5 and 2.0 (moderately-slender walls), moderate and high shear stress ratios, and significant contributions of shear deformations to total lateral displacement. Major specimen characteristics are presented in Table 1, whereas detailed descriptions of the experimental study and test results are presented by Tran and Wallace [3].

\section{ANALYTICAL MODELING STUDIES}

Detailed comparisons between experimentally measured and analytically predicted global and local wall responses for specimens SP2 (aspect ratio $=2.0)$ and SP4 (aspect ratio $=1.5$ ) are presented; including lateral load versus total, flexural, and shear displacements at the top of the walls, shear and flexural deformation profiles along wall height, and distribution of vertical (flexural) strains at the wall base.

\subsection{Finite element model generation}

Experimentally applied cyclic top displacement histories for each specimen, which consisted of three cycles for each drift level, were applied to the analytical model to replicate each test. A constant axial load value of approximately $663 \mathrm{kN}$ was applied at the top of the wall model for both specimens to replicate the average resultant of vertical forces applied by actuators during testing. Concrete and steel material models were calibrated

Table 1: Properties of test specimens.

\begin{tabular}{|c|c|c|c|c|c|c|c|c|c|c|}
\hline \multirow{2}{*}{$\begin{array}{l}\text { Test } \\
\text { No. }{ }^{(1)}\end{array}$} & \multirow{2}{*}{$\begin{array}{l}\text { Specimen } \\
\text { code }\end{array}$} & \multirow{2}{*}{$\begin{array}{c}\mathrm{h}_{\mathrm{w}} \\
(\mathrm{mm})\end{array}$} & \multirow{2}{*}{$\frac{h_{w}{ }^{(2)}}{l_{w}}$} & \multirow{2}{*}{$\frac{P_{a x}}{A_{g} f^{\prime}{ }_{c}}$} & \multicolumn{2}{|c|}{$\begin{array}{c}\text { Web } \\
\text { Reinforcement }{ }^{(3)}\end{array}$} & \multicolumn{2}{|c|}{$\begin{array}{c}\text { Boundary } \\
\text { Reinf. }{ }^{(3)} \\
\end{array}$} & \multirow{2}{*}{$\frac{V @ M_{n}}{V_{n}}$} & \multirow{2}{*}{$\frac{V @ M_{n}}{A_{c v} \sqrt{f^{\prime}}}$} \\
\hline & & & & & $\begin{array}{l}\rho_{\mathrm{t}}=\rho_{1} \\
(\%)\end{array}$ & configuration & $\begin{array}{c}\rho_{b} \\
(\%) \\
\end{array}$ & conf. & & \\
\hline SP2 & $\begin{array}{c}\text { RW-A20- } \\
\text { P10-S63 }\end{array}$ & 2440 & 2.0 & 0.073 & 0.61 & 2\#3@152 mm & 7.11 & $8 \# 6$ & 0.91 & 6.1 \\
\hline SP4 & $\begin{array}{c}\text { RW-A15- } \\
\text { P10-S78 }\end{array}$ & 1830 & 1.5 & 0.064 & 0.73 & 2\#3@127 mm & 6.06 & $\begin{array}{r}4 \# 6 \\
+4 \# 5 \\
\end{array}$ & 0.85 & 7.0 \\
\hline
\end{tabular}

(1) Used in further text when referring to test specimens

(2) $l_{w}=1220 \mathrm{~mm}, t_{w}=152 \mathrm{~mm}$ for both specimens

(3) US bar sizes called out 
using the procedure described by Orakcal and Wallace [4] to match corresponding specimen material properties obtained from uniaxial material tests. Geometry of the specimens in horizontal direction was discretized using ten model elements in the horizontal direction, where two elements were used to model each boundary element (confined concrete) and six elements were used in the web (unconfined concrete), as illustrated in Fig. 3b. Along the specimen height, sixteen and twelve model elements were used for specimen SP2 and SP4, respectively, where model element height was selected so the aspect ratio of each element is approximately equal to 1.0 (Fig. 3a). Reinforcing steel was distributed uniformly throughout each boundary and web element in both vertical and horizontal directions, where the reinforcing ratios used is calculated based on the reinforcement configuration reported by Tran and Wallace [3].

\subsection{Lateral load versus top displacement responses}

The comparisons of lateral load versus top wall displacement responses for specimens SP2 and SP4 obtained from the experiments and the analyses are presented in Fig. 4. It can be observed from the figure that major hysteretic characteristics of the load-deformation response are well predicted by the analytical model, including wall yield and ultimate lateral load capacity, stiffness, cyclic degradation of unloading/reloading stiffness, and overall shape of the hysteretic loops (pinching characteristics and plastic displacements at zero lateral load). Wall stiffness at lateral drift levels lower than $0.5 \%$ is slightly overestimated, which is very common in analysis of structural walls because the majority of analytical models do not account for effects of micro-cracking in concrete and strain penetration effects. Furthermore, the model captures the initiation of lateral strength degradation of specimen SP4 (see Section 4.4.3) during the loading cycle to a lateral drift ratio of $3.0 \%$, suggesting that the model is capable of predicting the wall lateral drift capacity reasonably well. However, significant strength loss observed during the experiments, initiated by concrete crushing and rebar buckling at wall boundaries followed by lateral instability of the wall compression zone for Specimen SP2 and shear sliding
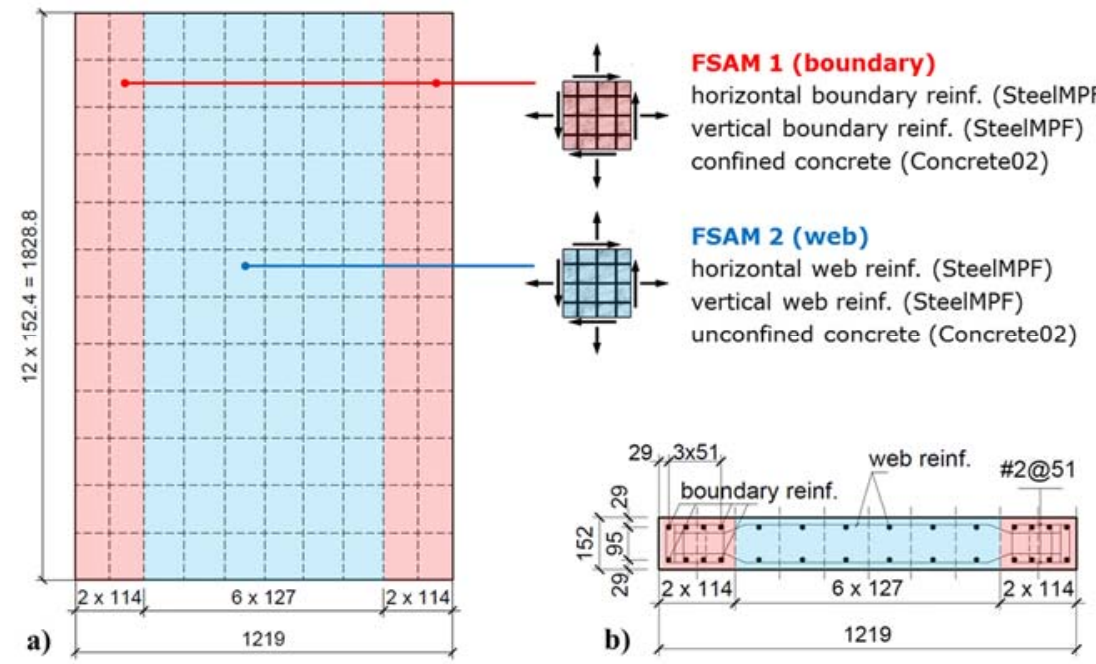

Figure 3: Wall discretization for specimen SP4. (a) Elevation with OpenSees material assignment and (b) Cross-section. 

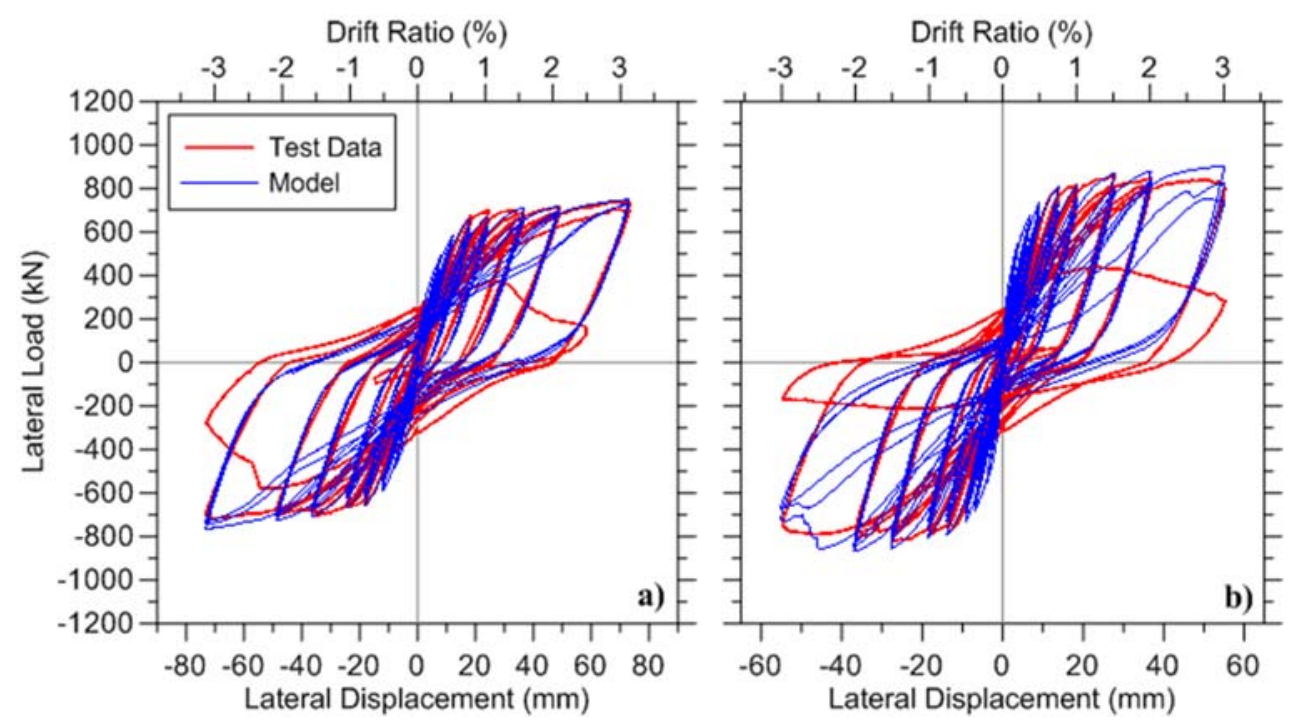

Figure 4: Lateral load versus wall top displacement. (a) SP2; and (b) SP4.

adjacent to the wall-pedestal interface for Specimen SP4, was not captured in analysis results because bar buckling, sliding shear, and lateral instability failure mechanisms are not implemented in the current modeling approach.

\subsection{Flexural and shear deformation components}

As mentioned earlier, contribution of shear deformations to total lateral displacements for the wall specimens considered was significant, suggesting that behavior of the wall specimens was influenced by shear-flexural interaction (SFI). In order to investigate the capability of the proposed modeling approach to capture this interaction, magnitudes and distributions of analytically obtained flexural and shear deformations are compared with experimentally measured responses in terms of load-deformation behavior and vertical profiles. Experimental shear and flexural deformation values were obtained from vertical and diagonal LVDT's during wall specimen testing using procedure described by Massone and Wallace [16]. Analytical shear deformations for each horizontal row of wall elements are calculated by integrating average shear strain (for the horizontal row of elements), whereas flexural deformations are obtained from by subtracting analytical shear deformations from the total lateral deformation.

\subsubsection{Load-deformation responses}

A representative comparison of experimentally measured and analytically predicted load versus flexural and load versus shear deformation responses for specimen SP4 is presented in Fig. 5, which indicates that analytical model is capable of capturing the presence of nonlinear shear deformations, as well as their coupling with nonlinear flexural deformations, through the entire cyclic loading history. Simultaneous occurrence of nonlinear shear and flexural deformations (at the same level of lateral load) reveals that SFI behavior is reflected in both analytical and experimental results. Furthermore, the relative magnitudes of the contributions of shear and flexural deformations are reasonably well 
predicted by the model for all of the loading cycles, where both experimental and analytical results suggest that contribution of shear deformations to the total lateral displacement of the wall is approximately $30 \%$ to $40 \%$. Analytical results diverge from the experimentally measured shear deformations only during the last loading cycle, as the model was unable to capture the sliding shear deformations observed along the base of both wall specimens near the end of the tests. This sliding deformation was not concentrated at the wall-foundation interface, but occurred over the highly damaged region near the wall base. Finally, the overall hysteretic shape of the shear and flexural load-deformation loops is well predicted by the model, where shear behavior is characterized with highly pinched hysteretic response, whereas no pinching is observed in the flexural hysteresis.

\subsubsection{Vertical deformation profiles}

Experimentally measured and analytically predicted vertical profiles of shear and flexural deformations (along wall specimen height) generated at selected peak top displacements corresponding to first loading cycles in positive and negative loading directions for specimen SP2, are presented in Fig. 6. It can be observed from Fig. 6(a) that in both experimental and analytical results, nonlinear flexural deformations (rotations) develop mostly within the bottom region of the wall along a height of $600 \mathrm{~mm}$, whereas the flexural displacement profiles are almost linear above this height, indicating that flexural deformations are relatively small in the upper regions of the wall. The magnitudes of flexural displacements along wall height are well predicted by the analytical model, with approximately 5\% deviation between model and test results. Furthermore, the comparisons shown in Fig. $6 \mathrm{~b}$ indicate that the shape of the measured and predicted shear deformation profiles for both specimens agree reasonably well, demonstrating that the model captures the experimentally observed concentration of shear deformations along the bottom $600 \mathrm{~mm}$ of the wall where nonlinear flexural deformations are measured. Therefore, the analytical

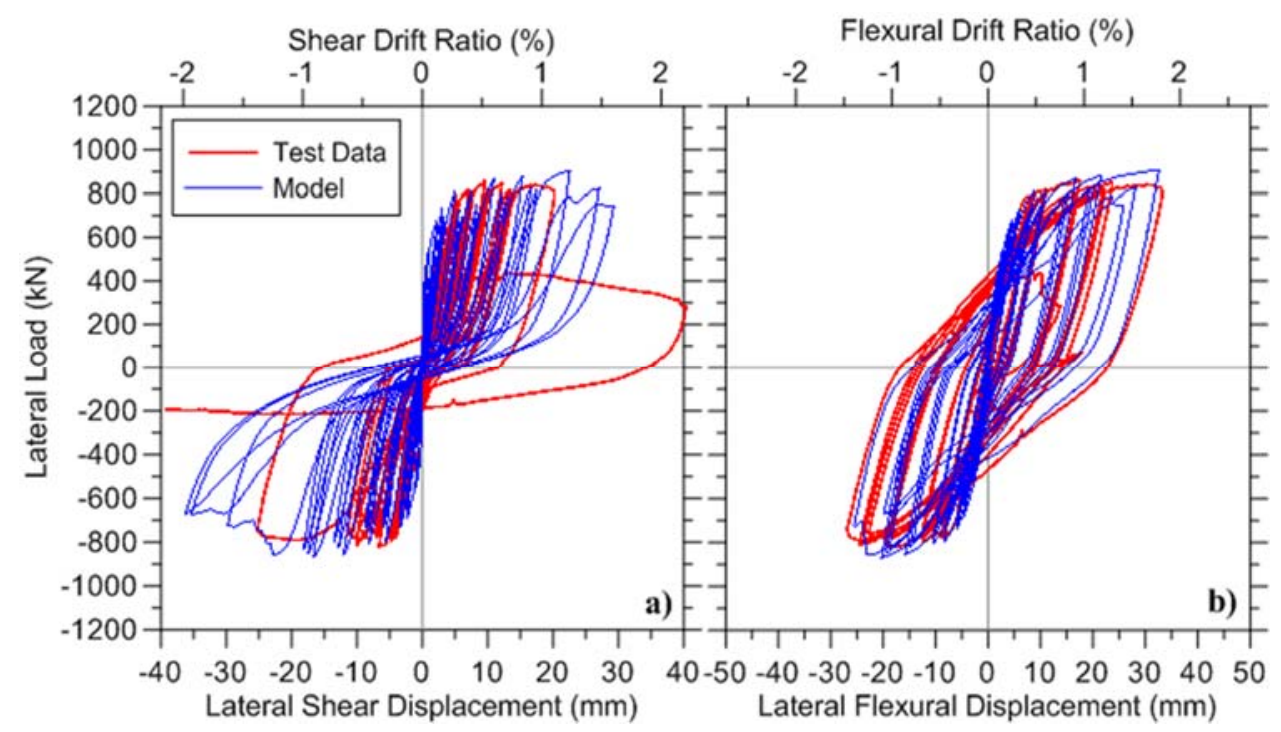

Figure 5: Lateral load versus top displacement components for specimen SP4. a) Shear; and b) Flexure. 

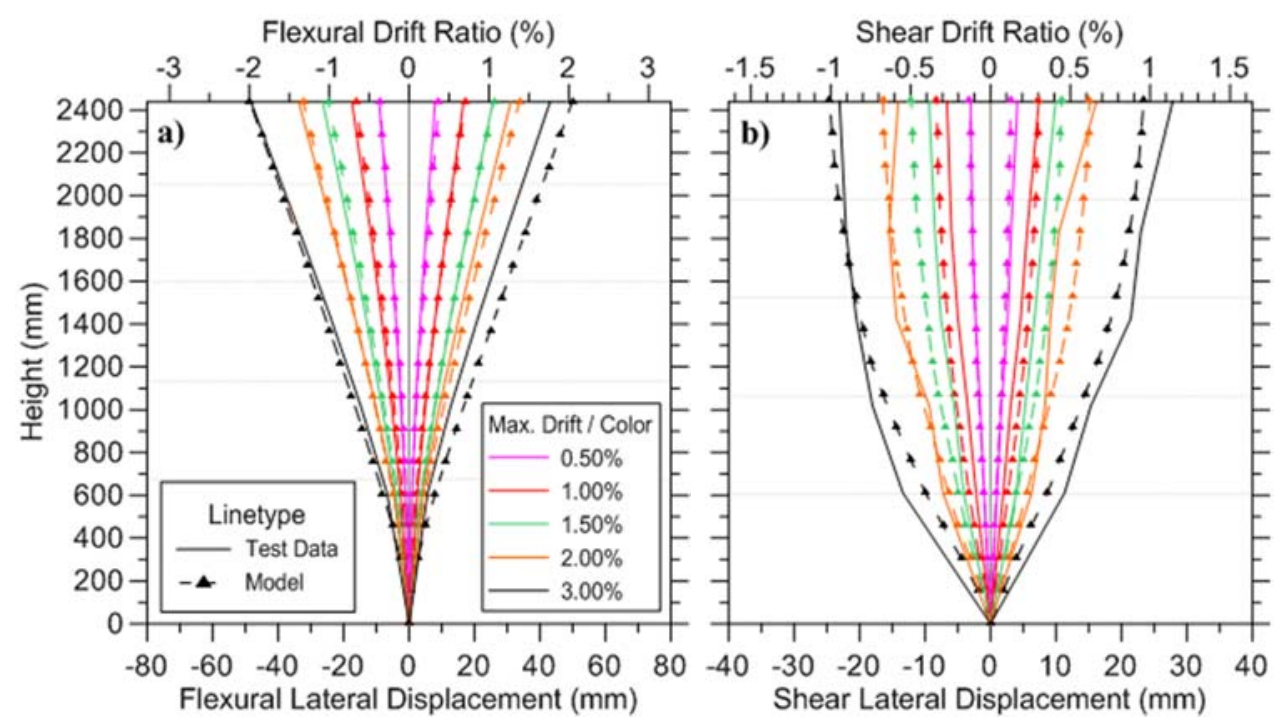

Figure 6: Deformation distribution along height of SP2. (a) Flexure; and (b) Shear.

model is capable of predicting nonlinear shear deformations developing even for a wall that yields in flexure, which has been also been observed in the current and previously conducted experimental studies (e.g., Tran and Wallace [3]; Massone and Wallace [16]; Oesterle et al. [17]), and provides another proof of capability of the model to capture experimentally observed SFI. The model reasonably predicts the magnitude of shear displacements along wall height at low and moderate drift levels in the positive loading direction for wall specimen SP2.

\subsection{Local wall responses}

Evaluation of the analytical model is further conducted by assessing local wall responses (i.e., strains and stresses) at various wall locations and by comparing them to the measured experimental data obtained for specimen SP4.

\subsubsection{Vertical deformation profiles}

Various analytically obtained and experimentally observed local wall responses for specimen SP4 are presented in Fig. 7 in order to describe overall characteristics of local response predictions obtained using the proposed modeling approach. Fig. 7a compares the experimentally-observed crack pattern recorded during testing at a drift ratio of 3.0\% (grey lines) and the crack orientations predicted by the analytical model (red lines). Crack orientations (directions perpendicular to the cracks) in the model formulation represent the directions along which the principal tensile strains first exceed the cracking strain of concrete within each model element. It can be observed from the figure that the analytically predicted orientation and distribution of cracks on the wall are in reasonable agreement with the experimentally observed crack pattern, suggesting that the cracking criteria and the orthogonal crack assumption of the model are both reasonable. The orientation of the cracks is more horizontal at the wall boundaries where flexural (vertical) strains predominate over shear strains, whereas the cracks are more inclined towards the middle of 
the wall web where shear (diagonal tension) strains are more dominant. As well, since flexural effects decrease along the wall height, orientation of the cracks at wall boundaries becomes more inclined towards the top of the wall.

Fig. $7 \mathrm{~b}$ and Fig. $7 \mathrm{c}$ further show analytically obtained field of vertical normal strains $\left(\varepsilon_{\mathrm{y}}\right)$ and shear stresses $\left(\tau_{\mathrm{xy}}\right)$ in the wall, respectively, corresponding to $3.0 \%$ lateral drift in the positive loading direction. As it can be observed in Fig. 7a, the distribution of vertical strains predicted by the model are reasonable, where tensile strains decrease over the height of the wall since the moment demand is decreasing linearly and the axial load is constant. As well, the predicted plastic hinge of the wall, where most of the nonlinear behavior is concentrated, is located approximately along the height of the bottom two elements ( 300 $\mathrm{mm} \approx l_{w} / 4$, commonly used plastic hinge length for walls with well-detailed boundaries), which is in agreement with the experimental observations by Tran and Wallace [3]. Furthermore, results presented in Fig. 7c show that shear stresses along the wall height develop mainly along the main diagonal compression strut, and that shear stresses are generally resisted by model elements that are subjected to axial compression (Fig. 7b), whereas elements subjected to tension resist zero (or very small) shear stress. This correlation between axial strains and shear stresses shown in Fig. 7b and Fig. 7c reveal the capability of the model to capture axial/flexural and shear interaction at section (local) response level in RC walls in addition to SFI that has been observed earlier from global analytical responses. It should be also mentioned that the level of shear stress in individual model elements reaches approximately $40 \sqrt{ } f^{\prime}$ c (Fig. 7c), which is significantly higher than the average (over the entire cross-section) shear stress of $7.0 \sqrt{ } f_{c}$ (Table 1) that would be obtained with models that do not capture shear-flexural interaction and are currently used in engineering practice for performance-based seismic design. Therefore, the proposed modeling approach provides improved analytical capabilities for capturing migration of local stress demands within the cross-section of structural wall subjected to lateral loads.

\subsubsection{Strain profiles along the wall base and vertical growth}

Fig. 8a presents a representative comparison between analytically and experimentally obtained vertical normal strain profiles along the wall base for specimen SP4, at selected drift levels. The experimental strains are measured over a vertical gauge length of $335 \mathrm{~mm}$ (14 in.) whereas the analytical results are obtained from the bottom $300 \mathrm{~mm}$ (12 in.),

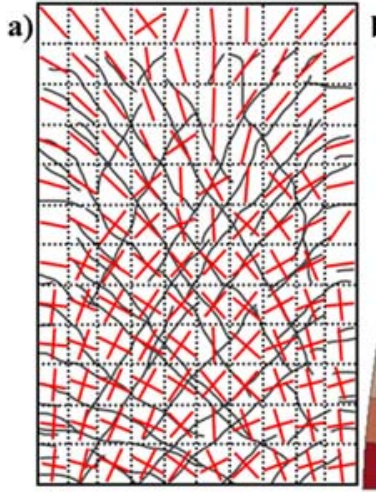

b)

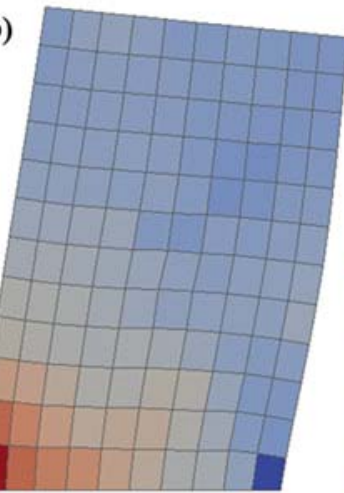

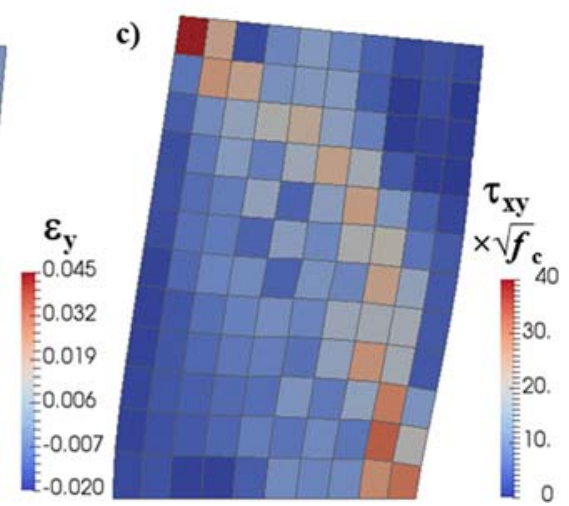

Figure 7: Strain and stress responses for specimen SP4 at 3.0\% drift. (a) Cracking pattern; (b) Vertical strain field; and (c) Shear stress field. 
corresponding to the total height of two bottom wall elements. Overall, the model provides reasonably accurate predictions of both compressive and tensile strains, as well as the location of the neutral axis on the wall cross section. Although relaxation of tensile strains at the wall boundary in tension is not predicted by the model, which leads to modest overestimation of tensile strains at large drift levels, the presented finite element modeling approach is capable of predicting the overall nonlinear distribution of strains along the wall base, which is not possible with macro-modeling approaches (which assume plane sections remain plane) typically used in engineering practice. This allows overall better prediction of wall strains, especially the compressive strains in concrete.

Comparison of analytical and experimental results for the relationship between vertical growth and lateral deformation at the top of wall specimen SP2 is shown in Fig. 8b. Vertical growth of the wall specimen during testing was caused by plastic (permanent) deformation of the boundary steel reinforcement. Analytical model results indicate an approximately constant vertical growth of the wall throughout the loading history and are in good correlation with experimentally measured data at both maximum applied lateral displacement and zero lateral displacement (i.e., residual vertical growth). Therefore, the proposed modeling approach and the constitutive material model adopted for steel describe the cyclic behavior of the boundary reinforcement within the plastic hinge region reasonably well.

\subsubsection{Strength loss prediction}

Tran and Wallace [3] reported that initiation of failure in specimen SP4 occurred due to crushing along diagonal strut (Fig. 9a), followed by crushing and rebar buckling in the wall boundaries (Fig. 9b), which led to sliding shear failure along the wall-pedestal interface of the wall. To illustrate the source of strength degradation in the model results, Fig. 9c shows the analytical stress-strain behavior of concrete along the diagonal strut (parallel to the crack) in the boundary model element, which clearly suggests degradation in the stressstrain relationship of concrete at this location. However, the complete failure mechanism observed during tests is not captured by the analytical model, due to the inability of the model to predict failure mechanisms associated with buckling of reinforcement and shear sliding.
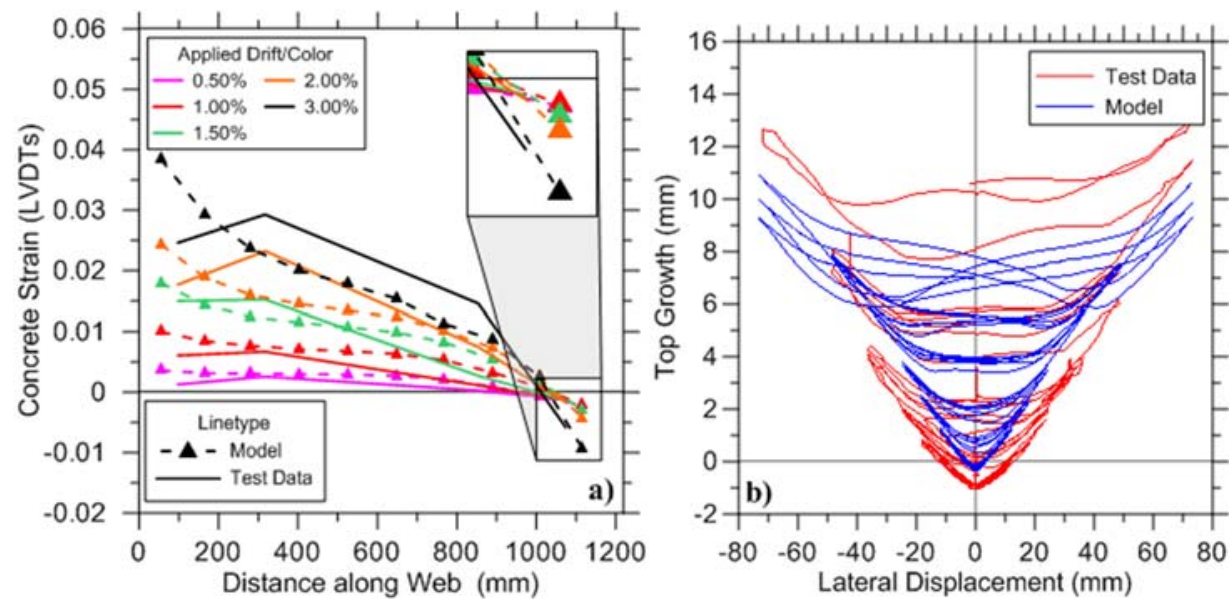

Figure 8: Local responses. (a) Vertical strain profiles along wall base specimen SP4; and (b) Vertical growth versus lateral top displacement for specimen SP2. 

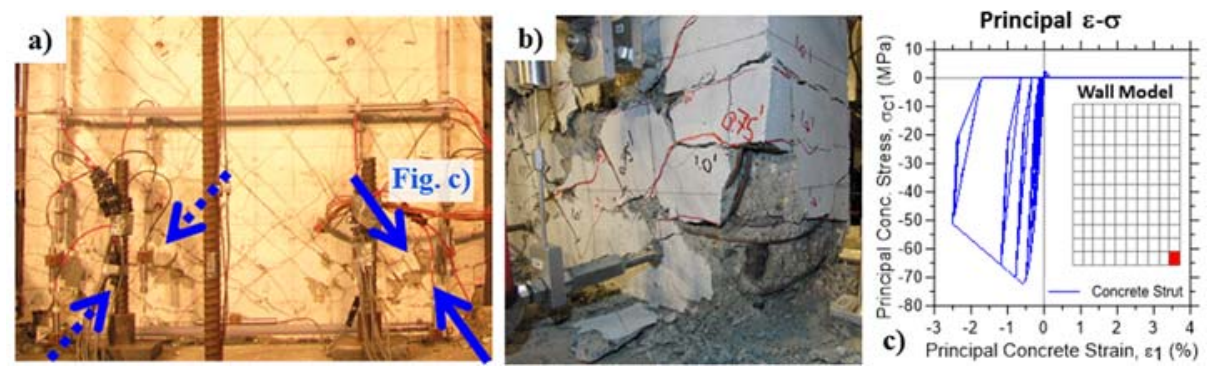

Figure 9: Predicted and observed wall boundary responses for specimen SP4 at 3.0\% drift. (a) Wall damage; (b) Boundary damage; (c) Predicted concrete behavior in principal direction.

\section{SUMMARY AND CONCLUSIONS}

A new finite element modeling approach for simulation of the nonlinear behavior of RC structural walls is described in this paper. The model incorporates a plane stress constitutive RC panel behavior described with a fixed-crack angle approach into a four-node quadrilateral finite element model formulation. The analytical model is implemented in the widely-used computational platform OpenSees.

Calibration and validation of the presented modeling approach is conducted using detailed experimental data recorded for two medium-rise RC wall specimens with aspect ratios of 1.5 and 2.0 tested under reversed-cyclic loading conditions. The behavior of the specimens was characterized with significant nonlinear shear deformations and pronounced shear-flexural interaction. Comparison between analytically obtained and experimentally measured wall responses was conducted at both global and local response levels, including load versus total, flexural and shear deformation responses, profiles of shear and flexural deformations at various drift levels along wall height, as well as local strain and stress distributions. Based on assessment of the model results, it can be concluded that the proposed modelling approach is capable of accurately simulating the cyclic global load-deformation behavior including strength, stiffness, and pinching of the walls investigated. The proposed model also successfully captures the experimentally measured magnitudes and distributions of flexural and shear deformations and shearflexural interaction. Unlike in fiber models, plane sections do not necessarily remain plane in the proposed finite element model formulation, which is more consistent with the experimentally-measured strain profiles and provides better predictions for the compressive strains in concrete, compared to fiber model formulations. Hence, both tensile and compressive strains are in good correlation with experimental data within the wall plastic hinge region, and the overall distribution of strains and stresses is reasonable.

Overall, the novel finite element modeling approach presented in this paper represents a promising approach for simulation of the nonlinear behavior of RC walls subjected to seismic actions. Future studies will involve extensive validation of the modeling approach against specimens with a wide range of wall characteristics, particularly aspect ratios, to assess model capabilities to accurately simulate the behavior of squat (shear-controlled) and slender (flexure-controlled) walls. The model is currently being extended to threedimensional problems with the objective to simulate the behavior of walls with various nonrectangular cross-sections (C-shaped, T-shaped, core walls) under earthquake loading. Development of user manuals, OpenSees Wiki pages, and examples is underway, and it is expected that the models will become publicly available by the end of 2018 . 


\section{ACKNOWLEDGEMENT}

This work was supported by the National Science Foundation, Award No. CMMI-1563577. Any opinions, findings, and conclusions expressed herein are those of the authors and do not necessarily reflect those of the sponsors.

\section{REFERENCES}

[1] ASCE 41-13, Seismic Evaluation and Retrofit of Existing Buildings, American Society of Civil Engineers, Reston, Virginia.

[2] LA Tall Buildings Structural Design Council, An Alternative Procedure for Seismic Analysis and Design of Tall Buildings Located in the Los Angeles Region, 2014.

[3] Tran, T.A. \& Wallace, J.W., Cyclic Testing of Moderate-Aspect-Ratio Reinforced Concrete Structural Walls. ACI Structural Journal, 112(6), pp. 653-665, 2015.

[4] Orakcal, K.\& Wallace, J.W., Flexural modeling of reinforced concrete walls - model calibration. ACI Structural Journal, 103(2), pp. 196-206, 2006.

[5] Kolozvari, K., Analytical Modeling of Cyclic Shear-Flexural Interaction in Reinforced Concrete Structural Walls. PhD issertation, UC Los Angeles, 2013.

[6] Massone, L.M., Orakcal, K. \& Wallace, J.W., Modeling of squat structural walls controlled by shear. ACI Structural Journal, 106(5), pp. 646-655, 2006.

[7] McKenna, F., Fenves, G.L., Scott, M.H. \& Jeremic, B., Open System for Earthquake Engineering Simulation (OpenSees), Pacific Earthquake Engineering Research Center, University of California, Berkeley, CA, 2000.

[8] Gullu, M.F. \& Orakcal, K., Nonlinear Finite Element Modeling of Reinforced Concrete Structural Walls. Proceedings, 16th World Conference on Earthquake Engineering, Santiago, Chile, 2017.

[9] Cook, D.R., Malkus, S.D., Plesha, E.M. \& Witt, J.R., Concepts and Applications of Finite Element Analysis, John Wiley \& Sons, 2001.

[10] Orakcal, K., Massone, L.M. \& Ulugtekin, D., Constitutive Modeling of Reinforced Concrete Panel Behavior under Cyclic Loading. Proceedings, 15th World Conference on Earthquake Engineering, Lisbon, Portugal, 2012.

[11] Vecchio, F.J. \& Collins, M.P., Compression response of cracked reinforced concrete. ASCE Journal of Structural Engineering, 83(2), pp. 219-231, 1993.

[12] Mansour, M.Y., Hsu, T.C. \& Lee, J.Y., Pinching effect in hysteretic loops of R/C shear elements. ACI Structural Journal, 205, pp. 293-321, 2002.

[13] Yassin, M.H.M., Nonlinear Analysis of Prestressed Concrete Structures Under Monotonic and Cyclic Loads. PhD dissertation, UC Berkeley, 1994.

[14] Menegotto, M. \& Pinto, E., Method of Analysis for Cyclically Loaded Reinforced Concrete Plane Frames Including Changes in Geometry and Non-Elastic Behavior of Elements under Combined Normal Force and Bending. Proceedings, IABSE Symposium, Lisbon, Portugal, 1973.

[15] Kolozvari, K., Orakcal, K. \& Wallace, J.W., Modeling of Cyclic Shear-Flexure Interaction in Reinforced Concrete Structural Walls. I: Theory. ASCE Journal of Structural Engineering, 141(5), 04014135, 2015.

[16] Massone, L.M. \& Wallace, J.W., Load - deformation responses of slender reinforced concrete walls. ACI Structural Journal, 101(1), pp. 103-113, 2004.

[17] Oesterle, R., Aristizabal-Ochoa J., Fiorato A., Russel H., and Corley W., Earthquake Resistant Structural Walls-Tests of Isolated Walls: Phase II. Portland Cement Association, Skokie, IL, 327, 1979. 